\title{
Dynamic Characteristics and Sensitivity Analysis of Test Machine Shaft
}

\author{
G. Wen, G. Y. Zhou, W. J. Wang, Z. L. Ying, C. G. He, Q. Y. Liu \\ Tribology Research Institute \\ State Key Laboratory of Traction Power \\ Southwest Jiaotong University \\ Chendu, China
}

\begin{abstract}
This paper presented the dynamic characteristics and sensitivity analysis of the shaft of test machine based on finite element method and orthogonal design method. It is concluded that the top eight order natural frequencies $(\mathrm{Hz})$ are 1673.3, 3666.6, 4421.8, 5713.8, 6612.9, 6656.8, 9550.9, 9617.5 based on modal analysis. The harmonic analysis results indicate that the third natural frequency is more likely to intensify initiation and propagation of the bending crack on the interference joint between specimen and shaft. It is concluded that the radius dimension parameters and the length parameters affecting more greatly the dynamic characteristics of shaft are R3, R1, R2 and L3, L4, L5, L1 through dynamic sensitivity analysis. The results above provide reference for dynamic optimization and design of the shaft and other shaft parts in the future.
\end{abstract}

Keywords- the shaft of test machine; dynamic characteristics; dynamic sensitivity analysis; finite element method; orthogonal test

\section{INTRODUCTION}

As important drive parts of the machines or equipments, the shafts have to bear large torque and bending moment in the operation process of the machine. There exits vibrations in all directions in operating process due to the error in the manufacturing and installation of shafts. And there are large amount of harm brought to the equipments by the vibrations, such as equipment malfunction problem, structure vibration strength problem, personnel health loss and efficiency problem, vibration reliability problems of complex equipment system, vibration noise and pollution of the environment and so on [1]. When the frequency of external excitation meets structural natural frequency, there is likely to produce resonance, as a result, it will lead to a greater response and cause more damage. In the design of structures, designers will investigate the dynamic characteristics and the dynamic response of structures under operating conditions [2-6]. So it is necessary to investigate its dynamic characteristics when designing the shafts. In this paper, taking the test machine shaft as the objective, its dynamic characteristics such as natural frequency, vibration mode were obtained by modal analysis, and the natural frequency the most affecting its dynamic characteristics was analyzed by harmonic analysis, then taking the frequency as an index, the dynamic sensitivity analysis was carried out to explore the effect of structural parameters on dynamic characteristics. The analysis results above provide reference for the dynamic optimization and design of shafts.

\section{DYNAMIC CHARACTERISTICS ANALYSIS OF SHAFTS BASED ON FEM}

\section{A. The Modal Analysis Results}

Firstly, the FEM (finite element method) mode was established in ANSYS. In the process of modeling, some parts of the shaft structure were simplified, such as, the chamfer, tool withdrawal groove and so on [7]

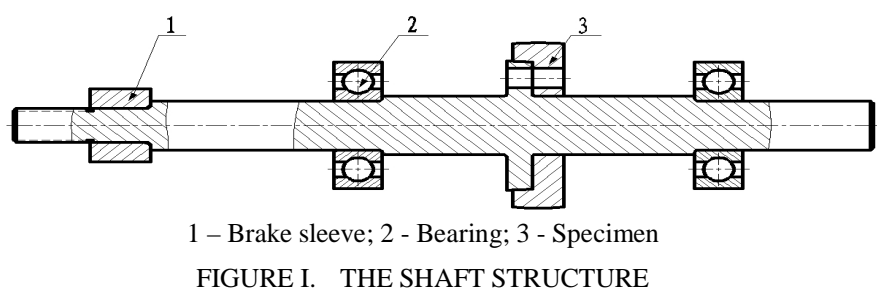

The material properties such as density, modulus of elasticity, Poisson's ratio are essential attributes of structures, and are independent of the geometric model [8]. In this paper, the material properties of the shaft structure are shown in Tab.

TABLE I. THE MATERIAL Properties OF THE SHAFT STRUCTURE

\begin{tabular}{cccc}
\hline $\begin{array}{c}\text { Material } \\
\text { properties }\end{array}$ & Density/Kg.m-3 & $\begin{array}{c}\text { Modulus of } \\
\text { elasticity/MPa }\end{array}$ & $\begin{array}{c}\text { Poisson's } \\
\text { ratio }\end{array}$ \\
\hline Value & $7.85 \times 10^{3}$ & $2.1 \times 10^{5}$ & 0.3 \\
\hline
\end{tabular}

In ANSYS, the shaft was simulated by solid45. Solid45 is 3D solid structural element with 8 nodes, every one of which has three degree of freedom along the three axles. The FEM model (shown in Fig. 2) was divided into 39840 elements by sweep.

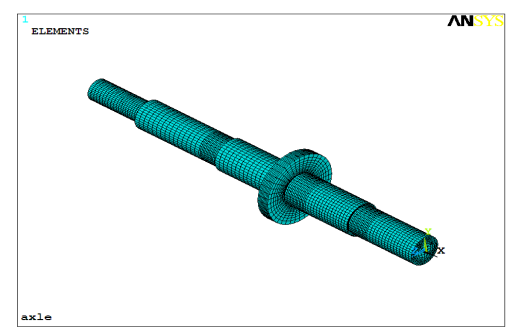

FIGURE II. THE FEM MODEL OF SHAFT 


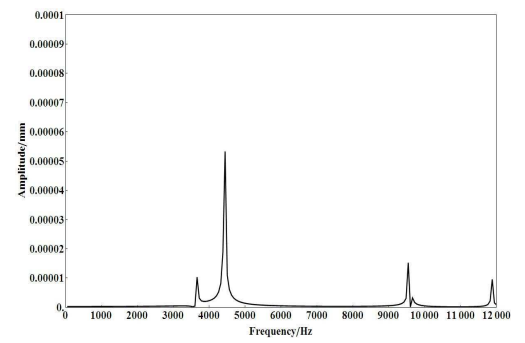

FIGURE III. THE DISPLACEMENT RESPONSE OF SHAFT

In this paper, assuming that the displacement in $\mathrm{Y}$ direction of nodes on interference between the brake set and the shaft is zero. In the analysis, the constraints were changed based upon literature [9] because of the changes in the shaft structure. By the vibration theory, the lower order modes play a more important role in the process of structure vibration than the higher order modes, so, only the first 8 order modal was analyzed in this paper. The analysis results are shown in Tab. 2.

TABLE II. ThE NATURAL FREQUENCY OF THE SHAFT

\begin{tabular}{ccccccccc}
\hline Order & $\mathbf{1}$ & $\mathbf{2}$ & $\mathbf{3}$ & $\mathbf{4}$ & $\mathbf{5}$ & $\mathbf{6}$ & $\mathbf{7}$ & $\mathbf{8}$ \\
\hline Frequenc & 167 & 366 & 442 & 571 & 661 & 665 & 955 & 96 \\
$\boldsymbol{y} / \boldsymbol{H z}$ & 3.3 & 6.6 & 1.8 & 3.8 & 2.9 & 6.8 & 0.9 & 17. \\
\hline
\end{tabular}

\section{B. Harmonic Response Analysis Results Based on FEM}

There was a fracture on the interference between shaft and specimen near the chamfer, where the response amplitude of the vertical displacement was investigated in this paper. Under the vertical dynamic loads with different vibration frequency, the displacement response peak appeared in the third mode (shown in Fig. 3). The results of modal analysis above show that the third mode is the swing up and down of the interference and the right end of the shaft. It is concluded that the third mode is easier to aggravate the initiation and propagation of bend cracks on the interference between shaft and specimen by modal and harmonic analysis.

\section{THE BASIC PRINCIPLE OF SENSITIVITY ANALYSIS BASED ON ORTHOGONAL TEST}

\section{A. The Basic Principle of Orthogonal Test [10]}

Orthogonal test is a method of engineering test design, it is one of the main methods to study and process multi-factors test and have the characteristics of neat comparison and evenly spreading [11].

Orthogonal table is the mathematical form constructed by combinatorial mathematics theory on the basis of thought of balance distribution. The orthogonal table is usually represented by the symbol " $L_{a}\left(b^{c}\right)$ ", where $L$ is the table, $a$ is the number of table rows, namely the test number, $b$ is the level number of factors, $c$ is the number of table columns, namely the number of factors. The orthogonal tables used in practical engineering application are $L_{4}\left(2^{3}\right)$ 、
$L_{8}\left(2^{7}\right) 、 L_{9}\left(3^{4}\right) 、 L_{25}\left(5^{6}\right)$ and so on. For the two levels orthogonal table, its structural rules are shown below:

$$
\left\{\begin{array}{c}
a=4 i \\
c=a-1
\end{array}\right.
$$

The commonly used two levels orthogonal tables are $L_{4}\left(2^{3}\right), \quad L_{8}\left(2^{7}\right), L_{12}\left(2^{11}\right)$ and so on. In sensitivity analysis, the orthogonal table with two levels is selected in general. It is easy to construct the orthogonal table automatically with the help of computers and can relatively reduce the number of experiments so as to improve the computing speed.

In the orthogonal test design, the quality level of factors can be determined by range analysis (R-method). The quality level of the factor $\mathrm{j}$ can be judged by analyzing the mean value $y_{j k}$ of all $\mathrm{j}$ level values corresponding to $\mathrm{y}$ factors. The quality level value of factors reflects the effect of factors on test indexes. If the optimal level value is bigger than the inferior, the effect of factors to indexes is positive, namely, the larger is the value of the factor, more advantageous to the index. The primary and secondary of the factors can be judged according to the range $R_{j}$ of factors. The range $R_{j}$ is given as follows:

$$
R_{j}=\max \left[\overline{y_{j 1}}, \overline{y_{j 2}}, \ldots\right]-\min \left[\overline{y_{j 1}}, \overline{y_{j 2}}, \ldots\right]
$$

B. The Basic Principle of Sensitivity Analysis Based on Orthogonal Test

At some point $x^{k}$, the sensitivity $S_{i j}$ of design function $\varphi_{i}(x)$ to design variable $x_{j}$ can be defined as:

$$
S_{i j}=\frac{\partial \varphi_{i}(x)}{\partial x_{j}} \mid x=x^{k}
$$

where $x$ is design variable, $\left|S_{i j}\right|$ is the sensitive degree of function $\varphi_{i}(x)$ to variable $x_{j}$, the value of $\left|S_{i j}\right|$ is bigger, the sensitivity is greater, taking the two level orthogonal table as the example, the value of $\left|S_{i j}\right|$ is given as follows:

$$
\left|S_{i j}\right|=\frac{R_{j}}{\left|x_{j 1}-x_{j 2}\right|}=\frac{\overline{y_{j 1}}-\overline{y_{j 2}}}{x_{j 1}-x_{j 2}}
$$

C. Dynamic Sensitivity Analysis Based on Orthogonal Test

The analysis results above show that the third mode has the greatest effect on the dynamic characteristics of the shaft. Taking the frequency as the index, the dynamic sensitivity about dimensional parameters (as shown in Fig. 4, radius dimension parameters and the length parameters are $D 1 \sim D 4$ and $L 1 \sim L 9$ ) was carried out. 


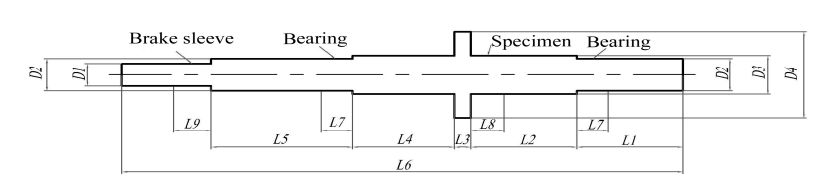

FIGURE IV. THE GRAPH FOR SHAFT STRUCTURE SIZE PARAMETERS
In analysis, a total of 13 parameters were considered. Based on the basic principle of orthogonal test, the standard orthogonal table $L_{16}\left(2^{15}\right)$ was decided to carry out the test, namely, a total of 16 experiments and 13 factors were arranged, and every one of the factors has two levels (as shown in Tab. 3). The test results are shown in Tab. 4.

TABLE III. THE LEVELS OF FACTORS IN DYNAMIC SENSITIVITY ANALYSIS

\begin{tabular}{cccccccccccccc}
\hline Factor & $\boldsymbol{R} \mathbf{1}$ & $\boldsymbol{R 2}$ & $\boldsymbol{R 3}$ & $\boldsymbol{R 4}$ & $\boldsymbol{L 1}$ & $\mathbf{L 2}$ & $\mathbf{L 3}$ & $\boldsymbol{L 4}$ & $\mathbf{L 5}$ & $\mathbf{L 6}$ & $\boldsymbol{L 7}$ & $\boldsymbol{L 8}$ & $\boldsymbol{L 9}$ \\
& & & & & & & & & & & & \\
\hline level1/mm & 7 & 10 & 12 & 26.6 & 51 & 51 & 8 & 49 & 68 & 270 & 15 & 16 & 18 \\
level2/mm & 8 & 11 & 13 & 27.6 & 52 & 52 & 9 & 50 & 69 & 271 & 16 & 17 & 19 \\
\hline
\end{tabular}

TABLE IV. THE DYNAMIC SENSITIVITY ANALYSIS RESUlts

\begin{tabular}{lllllllllllllll}
\hline Factors & $\boldsymbol{r} \mathbf{1}$ & $\boldsymbol{r} \mathbf{2}$ & $\boldsymbol{r 3}$ & $\boldsymbol{r 4}$ & $\boldsymbol{l 1}$ & $\boldsymbol{l 2}$ & $\boldsymbol{l 3}$ & $\boldsymbol{l 4}$ & $\boldsymbol{l 5}$ & $\boldsymbol{l 6}$ & $\boldsymbol{l 7}$ & $\boldsymbol{l} \boldsymbol{l}$ & $\boldsymbol{l 9}$ & $\begin{array}{c}\text { Test } \\
\text { Results/Hz }\end{array}$ \\
\hline Test 1 & 1 & 1 & 1 & 1 & 1 & 1 & 1 & 1 & 1 & 1 & 1 & 1 & 1 & 4421.8 \\
Test 2 & 1 & 1 & 1 & 1 & 1 & 1 & 1 & 2 & 2 & 2 & 2 & 2 & 2 & 4328.9 \\
Test 3 & 1 & 1 & 1 & 2 & 2 & 2 & 2 & 1 & 1 & 1 & 1 & 2 & 2 & 4321.6 \\
Test 4 & 1 & 1 & 1 & 2 & 2 & 2 & 2 & 2 & 2 & 2 & 2 & 1 & 1 & 4223.5 \\
Test 5 & 1 & 2 & 2 & 1 & 1 & 2 & 2 & 1 & 1 & 2 & 2 & 1 & 1 & 4528.1 \\
Test 6 & 1 & 2 & 2 & 1 & 1 & 2 & 2 & 2 & 2 & 1 & 1 & 2 & 2 & 4439.4 \\
Test 7 & 1 & 2 & 2 & 2 & 2 & 1 & 1 & 1 & 1 & 2 & 2 & 2 & 2 & 4574.0 \\
Test 8 & 1 & 2 & 2 & 2 & 2 & 1 & 1 & 2 & 2 & 1 & 1 & 1 & 1 & 4472.9 \\
Test 9 & 2 & 1 & 2 & 1 & 2 & 1 & 2 & 1 & 2 & 1 & 2 & 1 & 2 & 4623.6 \\
Test 10 & 2 & 1 & 2 & 1 & 2 & 1 & 2 & 2 & 1 & 2 & 1 & 2 & 1 & 4584.8 \\
Test 11 & 2 & 1 & 2 & 2 & 1 & 2 & 1 & 1 & 2 & 1 & 2 & 2 & 1 & 4713.2 \\
Test12 & 2 & 1 & 2 & 2 & 1 & 2 & 1 & 2 & 1 & 2 & 1 & 1 & 2 & 4662.1 \\
Test13 & 2 & 2 & 1 & 1 & 2 & 2 & 1 & 1 & 2 & 2 & 1 & 1 & 2 & 4381.6 \\
Test14 & 2 & 2 & 1 & 1 & 2 & 2 & 1 & 2 & 1 & 1 & 2 & 2 & 1 & 4356.3 \\
Test15 & 2 & 2 & 1 & 2 & 1 & 1 & 2 & 1 & 2 & 2 & 1 & 2 & 1 & 4320.8 \\
Test16 & 2 & 2 & 1 & 2 & 1 & 1 & 2 & 2 & 1 & 1 & 2 & 1 & 2 & 4297.9 \\
\hline
\end{tabular}

TABLE V. The DynAmic SENSITIVITy ANALYSIS RESUlts.

\begin{tabular}{|c|c|c|c|c|c|c|c|c|c|c|c|c|c|}
\hline Factors & r1 & $\mathbf{r} 2$ & r3 & r4 & 11 & 12 & 13 & 14 & 15 & 16 & 17 & 18 & 19 \\
\hline $\begin{array}{c}\text { Mean } \\
\text { value } 1\end{array}$ & 4413.8 & 4484.9 & 4331.6 & 4458.1 & 4464.0 & 4453.1 & 4488.9 & 4485.6 & 4468.3 & 4455.8 & 4450.6 & 4451.4 & 4452.7 \\
\hline $\begin{array}{c}\text { Mean } \\
\text { value } 2\end{array}$ & 4492.5 & 4421.4 & 4574.8 & 4448.3 & 4442.3 & 4453.2 & 4417.5 & 4420.7 & 4438.0 & 4450.5 & 4455.7 & 4454.9 & 4453.6 \\
\hline Range & 78.700 & 63.500 & $\begin{array}{c}243.20 \\
0\end{array}$ & 9.8000 & 21.700 & $\begin{array}{c}0.1000 \\
0\end{array}$ & 71.400 & 64.900 & 30.300 & 5.3000 & 5.1000 & 3.5000 & $\begin{array}{c}0.9000 \\
0\end{array}$ \\
\hline
\end{tabular}

\section{CONClusions}

This paper presented the dynamic characteristics and sensitivity analysis of the shaft of test machine based on finite element method and orthogonal design method. The following results were obtained from the detailed analysis.

(1) The top eight natural frequencies obtained from the modal analysis are $(\mathrm{Hz})$ : 1673.3, 3666.6, 4421.8, 5713.8, $6612.9,6656.8,9550.9,9617.5$.

(2) The results obtained from the harmonic analysis is that the third mode is easier to aggravate the initiation and propagation of bend cracks on the interference between shaft and specimen.

(3) Taking the third natural frequency as the index, the dynamic analysis was carried out. The analysis results indicate that the radius dimension parameters and the length parameters affecting more greatly the dynamic characteristics of shaft are $R 3, R 1, R 2$ and $L 3, L 4, L 5, L 1$.

The analysis results above provide the reference for the dynamic optimization and design of the shaft and other shaft parts. 


\section{ACKNOWLEDGEMENTS}

The work is supported by project supported by the National Natural Science Foundation of China (No. 51475393), the Innovative Research Teams in Universities (No.IRT1178), the science and technology innovation project supported by Fundamental Research Funds for the Central Universities (No.SWJTU12CX037) and independent research project of the State Key Laboratory (No.TPL1301).

\section{REFERENCES}

[1] LIU Wen-guang, CHEN Guo-ping, HE Hong-lin, et al. Review of studying on vibration fatigue[J]. Chinese journal of engineering design, 2012, 02, 19(1): 1-8.

[2] Liu Shuguo, Ma Yanhong, Zhang Dayi, et al. Studies on dynamic characteristics of the joint in the aero-engine rotor system[J]. Mechanical Systems and Signal Processing 2012,29:120-136.

[3] Lia L J, Xie Z H, Guo Y C, et al. Structural optimization and dynamic analysis for double-layer spherical reticulated shell structures[J]. Journal of Constructional Steel Research 2006,62: 943-949.

[4] Yi J, Zhang J W, Li Q S. Dynamic characteristics and wind-induced responses of a super-tall building during typhoons[J]. J. WindEng. Ind. Aerodyn. 2013,121:116-130.

[5] Shang Y J, Lin J Z, Liu X J, et al. Dynamic analysis of electric spindle device of a gantry planar grinding machine [J]. Manufacturing Technology \& Machine Tool, 2014,(02) : 43-47.

[6] Bielor E, Brettschuh W, Krutzik N J, et al. Dynamic characteristics and structural response of the SWR 1000 under earthquake loading conditions[J]. Nuclear Engineering and Design 2001,207: 77-93.

[7] LI Wei-guang, WANG Guo-he. Modal analysis of power-axis milling for turning-milling MC[J]. Machinery design \& manufacture, 2011(3): 169-171.

[8] Shu Biao, Yu Daoyuan, Wang Deng, et al. Model analysis of gear shaft based on UG, HyperMesh and ANSYS [J]. Modern Manufacturing Engineering, 2012(2): 71-73.

[9] WEN Guang, ZHOU Gui-yuan, WANG Juan, et al. Dynamics analysis of test machine shaft based on finite element method[J]. Machinery design \& manufacture, 2013, 07(07): 137-139.

[10] QIU Qingying, FENG Peien. A method of sensitivity analysis based on orthogonal test[J]. Journal of machine design, 1997(5): 4-7.

[11] LI Bo. Orthogonal experiment analysis on transmission performance of space lubricated harmonic drive $[\mathrm{J}]$. Journal of mechanical engineering, 2012, 02, 48(3): 82-87. 